\title{
Quando o plantio de feijão nos atravessa: experiências e experimentações nas ciências naturais no campo
}

\begin{abstract}
Resumo: Este artigo versa sobre um recorte de nossa pesquisa cartográfica, advinda de uma memória escolar vivenciada no Ensino Fundamental: o experimento que se propunha acompanhar o processo de germinação do feijão em um recipiente com algodão umedecido. A realização desse experimento provocou atravessamentos que causaram incômodos e nos mobilizaram a construir nossa escrita tomando esta memória como a potência da qual partem as reflexões em torno da noção de experiência (a partir dos escritos de Jorge Larrosa). Pensando nos atravessamentos que esta memória vem produzindo em nosso estar-sendo professoras, propomos como objetivo deste estudo acompanhar os processos de produção de memórias docentes, que visem expressar professoralidades no campo, considerando as entrevistas narrativas, articuladas a imagens visuais, como dispositivos para "fazer ver e fazer falar", tomando Gilles Deleuze como inspiração. Neste artigo, chamamos à conversa uma professora de uma escola no campo, a fim de acompanhar a produção de diferenças que permeiam nossas professoralidades, por meio de nossas memórias e dos acontecimentos que nos atravessam. Compreender a diferença como base do nosso processo de (trans)formação professoral, nos permitiu refletir sobre o fato de que ela é responsável pelos acordos e tensionamentos estabelecidos nos docentes por meio da experiência, que é o mote deste plantio cartográfico. Através da partilha de experiências, pudemos perceber que há muito de coletivo em nossos atravessamentos pessoais, afetando nossas professoralidades, ainda que de maneiras distintas.
\end{abstract}

Palavras-chave: Educação. cartografia; (auto)biografia; experiência imagética.

\section{Semeando em nosso plantio cartográfico}

O presente trabalho, escrito numa perspectiva rizomática deleuziana (DELEUZE; GUATTARI, 2011), decorre de uma pesquisa que visou uma reflexão sobre a produção de diferenças em nosso "estar sendo professoras". (PEREIRA, 2016) Fruto do que nominamos um plantio dissertativo, em que nos desafiamos a cartografar, junto a professoras de uma escola do campo, memórias docentes que tem nos atravessado a um repensar o ensino de ciências nesta escola.

Essa cartografia decorre de uma memória de infância, em que a primeira autora deste artigo experimentou uma vivência escolar que se tornou um acontecimento: o dia em que, numa aula de ciências, uma professora do Ensino Fundamental convida seus alunos, crianças "da roça", a plantar feijão num algodão. Esse experimento, muito recorrente nos livros didáticos de ciências, pouco
Eliziane Santana dos Santos Universidade Estadual de Feira de Santana (UEFS)

lee_santanafsa@hotmail.com Alessandra Alexandre Freixo Universidade Estadual de Feira de Santana aafreixo@uefs.br 
fazia sentido para crianças que, naquela época, cotidianamente plantavam seus feijões na terra, os viam brotar da terra.

Ao longo de suas trajetórias escolares, estudantes do campo experimentam uma vivência escolar que pouco contempla a realidade da qual fazem parte, realidade em que desde cedo sentimos os sabores e aprendizados de plantar e colher o próprio sustento da família. Assim, torna-se premente coletivizar ou intersubjetivar estas experiências que, como nos inspira Jorge Larrosa (2011), são únicas, mas que de algum modo dialogam ou se entrecruzam na formação dos sujeitos da experiência.

Tomamos nestes escritos a memória do feijão a germinar no algodão, nos idos do Ensino Fundamental, como uma "memória projetiva", que, como defende Marcos Vilela Pereira (2016) nos desestabiliza, deixando aflorar acontecimentos que nos atravessam:

[...] a memória projetiva é de mais complexo acesso. Deixamos o campo mais estável das representações sobre o vivido e penetramos no campo efervescente das forças vivas, o campo de caos-zero-deserto de onde aparecem as possibilidades e os acontecimentos que vazam nas coisas, nas gentes e nos fatos. (PEREIRA, 2016, p. 75)

Essa memória tornou-se um acontecimento: aquele dia em que, numa aula de ciências, uma professora do Ensino Fundamental convida seus alunos, todos meus colegas, crianças "da roça", a plantar feijão num algodão. De acordo com Larrosa (2018, p. 22) "[...] o acontecimento nos é dado na forma de choque, do estímulo, da sensação pura, na forma da vivência instantânea, pontual e fragmentada".

Os anos se passaram e a memória desse acontecimento permanece, a lembrança vinha como aqueles dias de sol a pino, em que o verde da safra vai se tornando amarelo e sem possibilidades de uma boa colheita. Dessa lembrança emerge essa cartografia, respaldada na memória como dispositivo e sua potência em afetar, buscando mapear os sentidos de nossos estar-sendo professoras, nossas professoralidades. (PEREIRA, 2016)

Nesse sentido, Marcos Vilela Pereira (2016) apresenta a noção de professoralidade, que nos será de grande valia neste percurso cartográfico:

[...] a professoralidade não é, a meu ver, uma identidade: ela é uma diferença produzida no sujeito. E, como diferença, não pode 
ser um estado estável a que chega o sujeito. A professoralidade é um estado em risco de desequilíbrio permanente. Se for um estado estável, estagnado redundaria numa identidade e o fluxo seria prejudicado. (PEREIRA, 2016, p. 35)

Nesse sentido, Pereira não se prende a um modelo de ser professor, mas investiga a professoralidade como um estado singular de referências e fatos profissionais que reverberam na esfera pessoal e vice-versa. Desse modo, optamos por basear a discussão na perspectiva da professoralidade trazida pelo autor, sobretudo por compreender que o estar-sendo professora inspira-se nas diferenças e nos atravessamentos produzidos em nós e que se modificam constantemente, já que não somos mais as mesmas professoras de ontem.

Pensando em todos os atravessamentos que a memória de um experimento de ciências vem produzindo em nosso estar-sendo professoras é que propomos como objetivo deste estudo acompanhar os processos de produção de memórias docentes, que visem expressar professoralidades no campo, tomando as entrevistas narrativas, articuladas a imagens visuais, como dispositivos para "fazer ver e fazer falar" Deleuze (1996, p. 1) sobre a produção de diferenças que a docência no campo produz em nós.

Para tanto, apresentamos a seguir algumas reflexões que nos mobilizaram ao longo desta cartografia, principalmente no que tange à compreensão das noções de experiência, experimento e experimentação, e ao modo como produzimos nossos dispositivos, ao convidar duas professoras a mapear conosco nossas professoralidades.

\section{Experiências e experimentações: contribuições de jorge larrosa para nossa cartografia...}

Nos dedicamos agora a pensar a noção de experiência a partir da ideia defendida por Jorge Larrosa, sobretudo no que diz respeito a compreensão de acontecimentos e afetações que não estão sob o nosso controle. Numa conversa tímida e sincera com Larrosa, encontramos o que parece ser o adubo ideal para fortalecer nosso plantio cartográfico:

E 'algo que não sou eu' significa também algo que não depende de mim, que não é uma projeção de mim mesmo, que não é 
resultado de minhas palavras, nem de minhas ideias, nem de minhas representações, nem de meus sentimentos, nem de meus projetos, nem de minhas intenções, que não depende nem do meu saber, nem de meu poder, nem de minha vontade. (LARROSA, 2011, p. 5, grifo do autor)

Recorremos aos estudos de Larrosa para melhor compreender a noção de experiência trazida por ele, quando o mesmo aponta que a experiência é a possibilidade de que algo nos toque e a forma como atribuímos ou não um sentido para tal. "A experiência é o que nos passa, o que nos acontece, o que nos toca. Não o que se passa, não o que acontece, ou o que toca. A cada dia se passam muitas coisas, porém, quase nada nos acontece". (LARROSA, 2002, p. 21) A esse respeito, o autor ainda complementa:

[...] o saber da experiência é um saber particular, subjetivo, relativo, contingente, pessoal. Se a experiência não é o que acontece, mas o que nos acontece, duas pessoas, ainda que enfrentem o mesmo acontecimento, não fazem a mesma experiência [...]. [...] ninguém pode aprender da experiência de outro, a menos que essa experiência seja de algum modo revivida e tornada própria. (LARROSA, 2002, p. 27)

Ao iniciar os primeiros escritos desta pesquisa, nos deparamos com narradoras de si e suas experiências, experiências entrelaçadas por sentidos e emoções. Nos desafiamos então a adentrar no universo de uma memória que por anos causou angústia, e precisamos revisitá-la por diversas vezes e, sobretudo, ressignificá-la ao buscar responder quais seus sentidos em nossas professoralidades. O que propomos aqui é o fomento à possibilidade de rupturas com o "ser professor", no intuito de desterritorializar um papel que aparenta estar definido, para assumirmos os atravessamentos vividos dentro e fora da escola.

\footnotetext{
A desterritorialização desses processos educativos nos leva a um posicionamento de escape a um controle imposto por regimes de verdade, para a produção de diferenças que, rizomaticamente, nos afastam da compartimentalização de saberes limitados em si mesmos. (VAZ, 2012, p. 8)
}

Assim, a desmistificação do "ser professor" se delineia no sentido de uma aprendizagem inventiva, que reveja, inclusive, a perspectiva curricular para uma formação efetivamente produtora de diferenças. 
Se entendermos que a experiência é o que nos acontece, podemos afirmar que ela está diretamente ligada ao que acontece com cada sujeito, ainda que ela seja vivida coletivamente, será única para cada um. De acordo com Larrosa (1994, p. 48), "[...] a experiência de si está constituída, em grande parte, a partir das narrações. O que somos ou, melhor ainda, o sentido de quem somos, depende das histórias que contamos e das que contamos a nós mesmos".

Partindo do pressuposto de que a aprendizagem se localiza tanto em um contexto formal quanto informal, é possível compreender que para além do contexto oficial e das instituições de ensino, as histórias de vida de cada sujeito interferem na produção de conhecimento. Com este entendimento, encontraremos espaços para pensar em questões concernentes não somente ao aspecto legal do cumprimento de conteúdo, como também nas nuances que efetivamente envolvem a vida dos estudantes.

Nesse sentido, compreendemos que ser-estar professor ultrapassa o exercício racional de práticas pedagógicas na escola, diz respeito também a tomar currículos como experiências através da ruptura com o padrão prescrito. Conceber o currículo como um elemento de apoio na produção de diferenças aponta para a ressignificação do mesmo, permitindo assim que o currículo narrativo também seja pensado como mais uma via de (trans)formação de professores(as).

No mundo contemporâneo, convivemos diariamente com a legitimação do conhecimento científico e a presença constante das tecnologias no cotidiano das pessoas e seus diversos contextos sociais. Nesse sentido, é importante considerar a atuação dos professores no que tange o ensino de ciências como um elemento fundamental para a compreensão do mundo e o reconhecimento da diversidade como parte dele. De acordo com Giordan (1999, p. 43): "É de conhecimento dos professores de ciências o fato de a experimentação despertar um forte interesse entre alunos de diversos níveis de escolarização".

Inspiradas em Jorge Larrosa, compreendemos ser necessário explicitar o sentido do emprego dos conceitos de experiência, experimento ou experimentação científica e experimentação cartográfica, visto que esses três termos permearam esta pesquisa. Assim sendo, a experiência pode ser definida como uma espécie de mediação entre o conhecimento e a vida humana. Em determinado momento da história, essa relação é questionada através da ciência experimental, como afirma Larrosa (2018, p. 33): 
Mas aí, a experiência converteu-se em experimento, isto é, em uma etapa no caminho seguro e previsível da ciência. A experiência já não é o que nos acontece e o modo como the atribuímos ou não um sentido, mas o modo como o mundo nos mostra sua cara legível, a série de regularidades a partir das quais podemos conhecer a verdade do que são as coisas e dominá-las.

A experimentação cartográfica, por sua vez, é um conceito utilizado para designar o que foi experimentado, sentido, vivido e saboreado pelo cartógrafo no processo de produção da pesquisa, espera-se que ele mergulhe em tudo isso para "[...] dar língua para afetos que pedem passagem". (ROLNIK, 2006, p. 23)

Remontando a uma memória de infância, afetada por estes conceitos, não procuramos aqui emitir juízo de valor sobre as professoralidades, mas compreender como o que as afeta para produzir, ou não, diferenças. Para isso, é imprescindível considerar que o ensino de ciências nos Anos Iniciais do Ensino Fundamental soma-se às demais disciplinas lecionadas por um(a) professor(a), o que faz com que pensemos se este(a) docente tem o aporte necessário para propor um ensino de ciências que contemple uma perspectiva curricular menos prescritiva. A esse respeito, Camargo, Blaszko e Ujiie, (2015, p. 2216) afirmam que:

[...] dentre as ações educativas voltadas ao Ensino de Ciências, destaca-se a importância de investir na formação docente de modo a refletir sobre os diversos saberes envolvidos nas práticas investigativas, que desperta o interesse dos alunos pelas ciências, enriquecendo o processo de aprendizagem e a formação de novos saberes.

Por hora, compreendemos que o ensino de ciências nos Anos Iniciais do Ensino Fundamental necessita estar diretamente relacionado com a formação docente, uma vez que transformações significativas e até mesmo históricas têm sido esboçadas, tanto no contexto prático da sala de aula quanto na abordagem de conteúdo.

\section{Nos caminhos da roça: construindo nossa cartografia entre narrativas (auto) biográficas}

Tanto tempo se passou e a lembrança do experimento da semente de feijão a germinar no algodão permanece viva na 
memória, porque não se restringiu ao enquadramento no tempo cronológico, como a narrativa de uma experiência que se inscreve em um tempo próprio.

A narração inscreve a experiência em uma temporalidade que não é do seu acontecer, mas da sua lembrança. Ao narrar, a pessoa cria um tempo próprio, que é o da própria vida, uma forma subjetiva de contar uma história por um caminho criado por ele mesmo. (FERREIRA, 2016, p. 54)

Quando acionamos essas memórias, não estamos analisando um fato isolado do passado. Ao revisitá-las, temos a oportunidade de reconstruir novas/outras percepções sobre a vida, sobre o mundo e o que temos sido. Nessa dinâmica, estamos envolvidas em tudo o que narramos, criando vida, já que a memória é a vida.

A memória é a vida, sempre carregada por grupos vivos e, nesse sentido, ela está em permanente evolução, aberta à dialética da lembrança e do esquecimento, inconsciente de suas deformações sucessivas, vulnerável a todos os usos e manipulações, susceptível de longas latências e de repentinas revitalizações. (NORA, 1993, p. 9)

Mesmo estando suscetíveis ao tempo cronológico, nossas memórias trilham sempre um caminho que está para além da linearidade desse tempo, do simples enquadramento em passado, presente e futuro. Como sujeitos de relações sociais, quase sempre nos tornamos reféns do tempo cronológico, assim como tudo o que há no mundo e acaba sendo tocado por ele.

Nessa perspectiva, recorremos mais uma vez aos estudos de Marcos Pereira para nortear nossas considerações acerca da memória, faremos uma analogia ao movimento deleuziano de territorialização e desterritorialização para entender os conceitos de "memória retentiva" e "memória projetiva". De acordo com Pereira (2016, p. 71), "[...] a memória retentiva trabalha no nível da repetição, da previsibilidade e, dessa forma, compreende-se que tenha sua forma regulada pelas regras do discurso, pelos princípios enrijecidos da lógica."

Desse modo, podemos inferir que o conceito de memória retentiva nos leva a uma territorialização, o que se faz necessário para que não estejamos sempre a nos perguntar quem somos nós e quem são as pessoas à nossa volta. O autor afirma ainda que: 
A memória retentiva, exercitada sozinha, contribui para o isolamento do indivíduo em um casulo identitário falsamente rijo, reforçando a concepção do sujeito como um ser estável e igual a si mesmo. Ela diz quem eu fui ou sou utilizando enunciados limitados aos modos de conjugações verbais, sobretudo ao indicativo. Ela circunscreve uma figura existencial em parâmetros supostamente universais e reforça o estabelecimento da intransigência: o que foi indica e sustenta o que é. (PEREIRA, 2016, p. 71, grifos do autor)

Por outro lado, há os movimentos de desterritorialização, que nos arrebatam ao movimento, de extrema importância para o nosso estar-sendo no mundo, entra em cena a memória projetiva, que nos desloca do nosso lugar.

Seu conteúdo é dado, predominantemente, pelas lacunas e pelas rupturas, as quais são a sua substância. As rupturas são os momentos de quebra, falência e dissolução das formas vigentes, isto é, uma ruptura é a eclosão de um clic que indica a inadequação entre o que se vinha sendo e a potência de vir a ser. (PEREIRA, 2016, p. 76)

Assim é a lembrança deste acontecimento - o "plantio" do feijão no algodão -, que se encontra no campo da memória projetiva, pois possui tanta potência que nos obriga a nos deslocar, dando início a esta cartografia. Pereira ainda afirma que:

No plano da memória projetiva, a ruptura é o ponto de desencadeamento de um novo movimento do ser, isto é, ela equivale ao alinhamento de certo número de diferenças e à eclosão de um acontecimento. [...] Vale dizer que nem sempre a ruptura é ruim ou má. Ela é má no sentido de vir a desinstalar uma ordem que já perdurava há certo tempo, isto é, no sentido de impelir à mudança (e mudar o que já está estabelecido e consolidado é algo difícil e sofrido). Porém, ela é instância de produção, de criação, e isso é bom. De qualquer modo, a vivência de uma ruptura, ainda que desejável, é uma experiência traumática que provoca certo desconforto e deixa marcas. (PEREIRA, 2016, p. 76)

Ao recordar um acontecimento, criamos mentalmente um ordenamento para que um venha depois ou ao mesmo tempo que os outros, esse ordenamento não segue necessariamente o tempo cronológico. A maneira como uma experiência nos atravessa, 
não é cronometrada em sequência, ela está relacionada com o esquema elaborado na subjetividade de cada um. As experiências narradas nesta cartografia aconteceram em diferentes períodos, que pouco ou nada importam, já que o atravessamento gerado por elas foi mais significativo que memorizar dia, mês e ano em que elas aconteceram.

A experiência não pode ser antecipada, não tem a ver com o tempo linear do planejamento, da previsão, da predição, da prescrição, esse tempo em que nada nos acontece, e sim com o acontecimento do que não se pode 'pre-ver', nem pre-escrever. Por isso, a experiência é sempre do que não se sabe, do que não se pode, do que não se quer, do que não depende de nosso saber, nem de nosso poder, nem de nossa vontade. (LARROSA, 2018, p. 69)

Nesse sentido, as experiências que narramos estão diretamente ligadas com a dimensão do que nos atravessa e com o sentido atribuído por cada um a estes atravessamentos a partir de nossas subjetividades. Para Ferreira (2016, p. 58, grifos do autor) "[...] a experiência como processo de (trans)formação permeia profissional-pessoal e torna-se uma unidade; dá-se ao longo da vida, na junção de todos os 'tempos." Vale ressaltar que a ruptura com o tempo cronológico contribuirá para que as cartógrafas construam uma temporalidade própria para narrar suas memórias.

A narrativa leva ao ouvinte as afetações trazidas por uma memória, e por isso se fez lembrada, e em certa medida também o faz com o(a) narrador(a), pois o acionamento de memórias e percepções feito pela narração contribuem para a (trans)formação de si, no mesmo movimento permite ao narrador/a transitar pelos tempos. De acordo com Souza (2004, p. 174), “[...] ao narrar-se, a pessoa parte dos sentidos, significados e representações estabelecidos à experiência. A arte de narrar, como uma descrição de si, instaura-se num processo metanarrativo porque expressa o que ficou na sua memória."

Vale ressaltar que, nesta cartografia, nos aliamos aos referenciais teórico-metodológicos da pesquisa com narrativas (auto)biográficas. O método (auto)biográfico considera os participantes como protagonistas de suas histórias, o que 1he confere um potencial de autoformação, ao passo que tem caminhado cada vez mais na direção de consolidar-se no cenário acadêmico. 
Nas pesquisas na área de educação adota-se a história de vida mais especificamente, o método autobiográfico e as narrativas de formação como movimento de investigação-formação, seja na formação inicial ou continuada de professores/professoras seja em pesquisas centradas nas memórias e autobiografias de professores. (SOUZA, 2006, p. 24)

Nesse sentido, a (auto)biografia tem se apresentado como um solo fértil no que diz respeito a (trans)formação docente, por permitir entre outras coisas descobrir-se a si mesmo, sobre o trabalho (auto)biográfico e seus instrumentos, Costa (2012, p. 3) afirma que "[...] revelam-se como importantes recursos para a descoberta de si, existindo assim a apropriação de trajetórias pessoais, constituindo um exercício para que as experiências de vida, de profissão, e de formação sejam refletidas no processo de formação docente."

\section{Percursos metodológicos: preparando o terreno}

Nesta pesquisa, optamos pelo método cartográfico para mapear memórias docentes, uma vez que para investigar a trajetória da constituição da professoralidade é necessário considerar também o campo imaterial de sua formação. Decidimos, assim, encarar o desafio de cartografar experiências docentes, por compreender que, como sugerem Passos e Barros (2015, p. 17, grifo do autor):

A Cartografia como método de pesquisa-intervenção pressupõe
uma orientação do trabalho do pesquisador que não se faz de
modo prescritivo, por regras já prontas nem com objetivos
previamente estabelecidos. No entanto, não se trata de uma ação
sem direção, já que a cartografia reverte o sentido tradicional de
método sem abrir mão da orientação do percurso da pesquisa.
O desafio é o de realizar uma reversão do sentido tradicional
de método - não mais um caminhar para alcançar metas pré-
fixadas (metá-hódos), mas o primado do caminhar que traça, no
percurso, suas metas.

Essa inversão de percursos, característica do método cartográfico, do (re)traçar as metas e objetivos a partir da caminhada na produção de dados, confere um caráter essencialmente coletivo ao pesquisar, que nos exige um novo posicionamento político-ético frente a nossos colaboradores, participantes nesta pesquisa, não mais tomados como sujeitos ou objetos da pesquisa, mas como 
copartícipes na produção desta pesquisa-intervenção. Esse posicionamento lança um novo olhar para a experiência do pesquisar, na medida em que pesquisar e intervir são elementos inseparáveis, o que requer uma inversão nas formas de conhecer a realidade: "[...] se trata de transformar para conhecer e não de conhecer para transformar a realidade". (PASSOS; BARROS, 2015, p. 18)

Se partirmos da premissa de que toda pesquisa é intervenção e de que o observador, ao observar, intervém na realidade e produz, institui objetos, compreenderemos que o método cartográfico "[...] exige do cartógrafo um mergulho no plano da experiência" (PASSOS; BARROS, 2015, p. 30), em que conhecer e fazer são inseparáveis, restando-nos o reconhecimento dos limites de nossos procedimentos metodológicos e da necessidade de inversão do sentido da pesquisa, apostando na construção do percurso metodológico à medida que caminhamos, que nos tornamos implicados ou afetados pela própria cartografia. Assim, cartografar é

[...] conhecer a realidade é acompanhar seu processo de constituição, o que não pode se realizar sem uma imersão no plano da experiência. Conhecer o caminho de constituição de dado objeto equivale a caminhar com esse objeto, constituir esse próprio caminho, constituir-se no caminho. Esse é o caminho da pesquisa-intervenção (PASSOS; BARROS, 2015, p. 30)

A cartografia social, aqui descrita, se refere ao método como estratégia de análise, de um olhar crítico que acompanha trajetórias e formações rizomáticas e liga-se aos campos do conhecimento. De acordo com Cintra e demais autores (2017), enquanto método de pesquisa, a cartografia é uma das possibilidades de estudar objetos de caráter mais subjetivo, que exigem do pesquisador a habitação de diferentes territórios. Percebemos então que o método cartográfico nos daria condições de enveredar pelas redes de sentimentos oriundos de memórias docentes, tais como aquela do feijão plantado no algodão.

Na cartografia, não se pode situar o campo de pesquisa como um lugar distante do cartógrafo. Nesse sentido, o cartógrafo está diretamente implicado no seu método de pesquisa, não há a possibilidade de manter-se neutro, e ele não o deseja. Ele se funde com o que pesquisa, o que faz parte da constituição da sua pesquisa.

A cartografia exige do pesquisador posturas singulares. Não coleta dados; ele os produz. Não julga; ele coloca em questão as forças que pedem julgamento. A cartografia ocupa-se de 
planos moventes, de campos que estão em contínuo movimento na medida em que o pesquisador se movimenta. Cartografar exige como condição primordial estar implicado no próprio movimento de pesquisa. (COSTA, 2014, p. 71)

Nesta cartografia, chamamos à nossa conversa uma professora, a fim de acompanhar a produção de diferenças que permeiam nossas professoralidades, por meio de nossas memórias e dos acontecimentos que nos atravessam. Na operação de mapeamento que recortamos para socializar neste trabalho, nos dedicamos às imagens visuais como dispositivos de "fazer falar". (DELEUZE, 1996, p. 1)

É importante ressaltar que não pretendemos abordar a imagem como uma representação, mas em uma perspectiva deleuziana compreender a sua potência criativa para o pensamento.

De modo que, nesta perspectiva, a imagem, enquanto imagemsensação, já não está no registro da representação e apresenta seu potencial próprio de produção de sensações e capacidade de incitar o pensamento, de fazer pensar. Esse tipo de imagem vai além da figuração, da ilustração; ele não apenas repete um objeto, ela é ela mesma um novo objeto, mas um objeto de sensações. (GALLO, 2016, p. 22)

Partindo de tal perspectiva, entendemos que as imagens se tornam uma gama de possibilidades que de algum modo dialogam com nossas trajetórias de vida e (trans)formação, no entrecruzamento destas com o mundo. A potência de uma experiência imagética permite outras formas de produzir subjetividades, desse modo, trazer uma experiência imagética para esta cartografia possibilita uma conversa direta entre nossas professoralidades, trajetórias e afetações.

\section{As imagens que atravessam nossas professoralidades}

Inicialmente, trazemos para a nossa conversa a imagem que é a potência desta cartografia (Figura 1). Como experimento científico que afetou uma estudante, hoje traz grandes delineamentos para nossa professoralidade e se tornou a experiência que tem nos atravessado atravessa. 


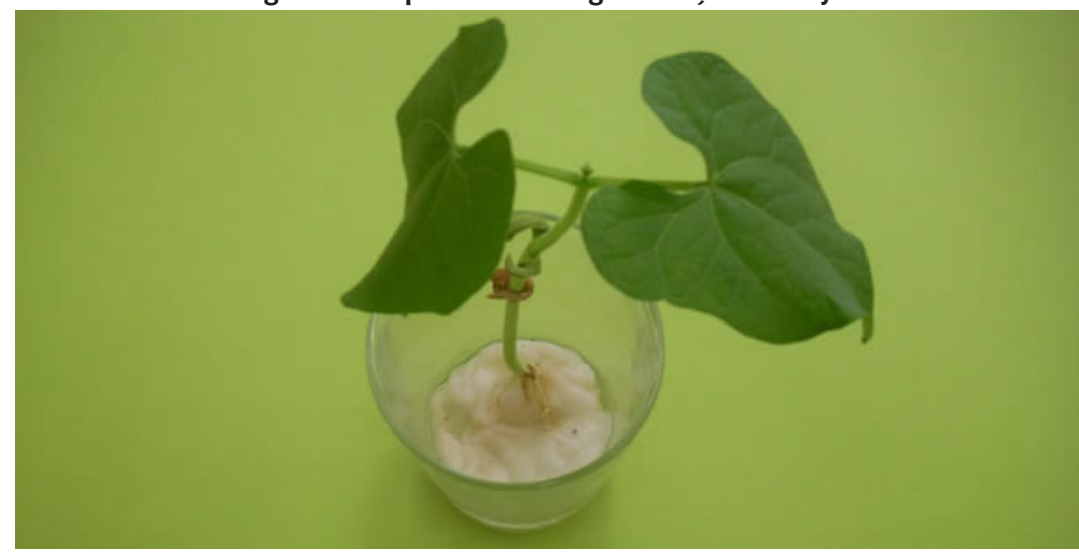

Fonte: Palandi (2016).

Pensando nas idiossincrasias de nossas professoralidades, incorporar às nossas conversas com a cartógrafa Alice, a imagem que nos atravessa, nos afeta e mobiliza a até aqui, trazendo outros devires à nossa professoralidade. A nossa intenção em utilizar o recurso imagético para expressar nossas afetações, justifica-se pelo fato de compreendermos que a potência imagética pode produzir experiências de (trans)formação em nossas trajetórias professorais.

Outro aspecto que vale a pena ser ressaltado diz respeito à potência das imagens como um dispositivo que mesmo sendo singular também tem o caráter de expressar coletividades, sobretudo no que diz respeito às nossas trajetórias professorais e as relações que as entremeiam. Nesse sentido, podemos dizer que a perspectiva pela qual optamos compreende que a imagem possui "força própria". (WUNDER, 2009, p. 71)

Uma de nossas conversas com Alice se iniciou pelo comparti1har dessa imagem, quando somos atravessadas por uma narrativa:

Infelizmente, ou não, as coisas mudaram por aqui, não é mais como no seu tempo. Quando eu cheguei aqui, eu falava sempre isso, que tinha dias que os meninos não vinham pra escola porque ajudavam na roça, mas hoje em dia ninguém ajuda mais não. Antigamente era assim, tinha o dia de não vir porque ia ajudar e hoje em dia essa relação mudou. (Alice)

Nossas "certezas", nossas compreensões em torno desta comunidade rural, vão sendo abaladas. O movimento das nossas "certezas" está relacionado com o imbricamento de sentimentos, lugares e forças que compõem nossa trajetória de vida, assim 
enquanto algumas destas "certezas" fazem conexões diversas, outras perdem o sentido e já não nos vemos mais enquadradas em um modelo ou um jeito de "ser" no mundo, este talvez seja um dos encaminhamentos para pensarmos sobre o fato de vivermos uma constante busca pelo novo.

Vale salientar que toda a experiência desse plantio cartográfico necessitou de tempo, o que nem sempre tínhamos a nossa disposição. Uma das dificuldades encontradas diz respeito ao que Larrosa (2002, p. 22) nos chama a atenção quando coloca a barreira construída pela era da informação em que vivemos, ou seja, no percurso fomos atropeladas pelas demandas de planejamento, avaliações e prazos institucionais que em alguma medida engessaram a proposta pretendida, "[...] a experiência é cada vez mais rara por falta de tempo. Tudo o que se passa, passa demasiadamente depressa, cada vez mais depressa". Precisamos algumas vezes remarcar os encontros e interromper as conversas, muitas eram as demandas da minha parceira de cartografia, era evidente que os prazos a sufocavam e em alguma medida interrompia a pretensa experiência deste plantio. Que experiência pode haver sem tempo?

Assim também é com a safra, ela precisa ser plantada e colhida no tempo certo, semear no período adequado, na comunidade rural em que produzimos nossa cartografia acredita-se que 19 de março, dia de São José, é a data ideal para o plantio, é a tentativa de que as sementes se desenvolvam no período em que o clima esteja mais favorável e a safra vingue, colher no tempo certo garante que o feijão esteja no ponto para a bata e que se encontre compradores para escoar a parte da produção que excede o consumo familiar, assim poderia dizer que o tempo da colheita é um atravessamento que precisa de tempo.

Além da experiência imagética que trazemos como a pontência desse plantio cartográfico, convidamos nossa parceira de cartografia a trazer para a nossa conversa uma imagem que expressasse os atravessamentos da sua professoralidade e devido ao pouco tempo, combinamos que o envio da mesma poderia ser feito através do aplicativo de mensagens WhatsApp. Seguimos nos comunicando, porém a falta de tempo mais uma vez engessou a experiência, a proposta da imagem parecia não the afetar, diante disso pedi que ela pensasse em uma imagem mental que de algum modo expressasse as marcas da sua trajetória professoral e fui ao seu encontro para mais uma conversa. 
Iniciamos a conversa na sala enquanto as crianças realizavam as atividades sob a supervisão da professora auxiliar, e de cara o assunto foi a corrida contra o tempo para dar conta das demandas que envolvem o final do ano letivo, fechamento de cadernetas, alimentar o sistema da Secretaria de Educação, correções, resultados e tantos os outros afazeres que envolvem sua vida fora da escola. Assim, ela começou a narrar a sua sensação perante a minha proposta:

Assim, pra ser sincera eu nunca tinha pensado sobre isso, sobre uma imagem, mas o que eu tenho como uma coisa marcante na minha trajetória como professora é que eu nunca pensei em desistir. Mesmo com todas as dificuldades que eu até já falei, mesmo tirando dinheiro do meu bolso e mesmo sem ter planejado ser professora, eu levei muito a sério desde o começo.

Em nossas conversas com Alice, percebemos o quanto "ter sido escolhida" pela docência a desafiou, sobretudo porque em suas falas há uma clareza de quem tem consciência de que precisa estar em movimento, em devir. Um movimento que se inicia quando a professora assume o trabalho em uma escola de distrito e com os recursos ainda mais escassos, e assume um caráter ainda mais complexo quando a escola é afetada pelo trabalho com as classes multisseriadas, dentre outros tantos acontecimentos. Sobre a ação de movimentar-se, Fernandes, Viana e Scareli (2016, p. 225) apontam que "[...] ser professor, tornar-se professor é não cessar de construir e reconstruir conexões. Encontros com a prática docente, encontros com o mundo. A multiplicidade do tornar-se professor movimenta-o eternamente e impede o enraizamento, o estado séssil".

Assim, entendemos que nossa parceira de cartografia não possui exatamente uma imagem que expresse a sua professoralidade, porém traz como marca da sua trajetória docente o fato de nunca ter pensado em desistir. Tal fato nos mobiliza de modo a pensar na nascente (Figura 2), que está localizada na comunidade rural em que se localiza a escola e que serviu por muitos anos como fonte de água, mesmo em tempos de seca. Essa nascente que insistentemente não desistia de fornecer a subsistência aos filhos das suas terras. É essa persistência que nos atravessa e se expressa por uma imagem: a nascente do rio, aquele rio de afetos que atravessa a terra e faz brotar o feijão, aquela nascente, em constante movimento. 


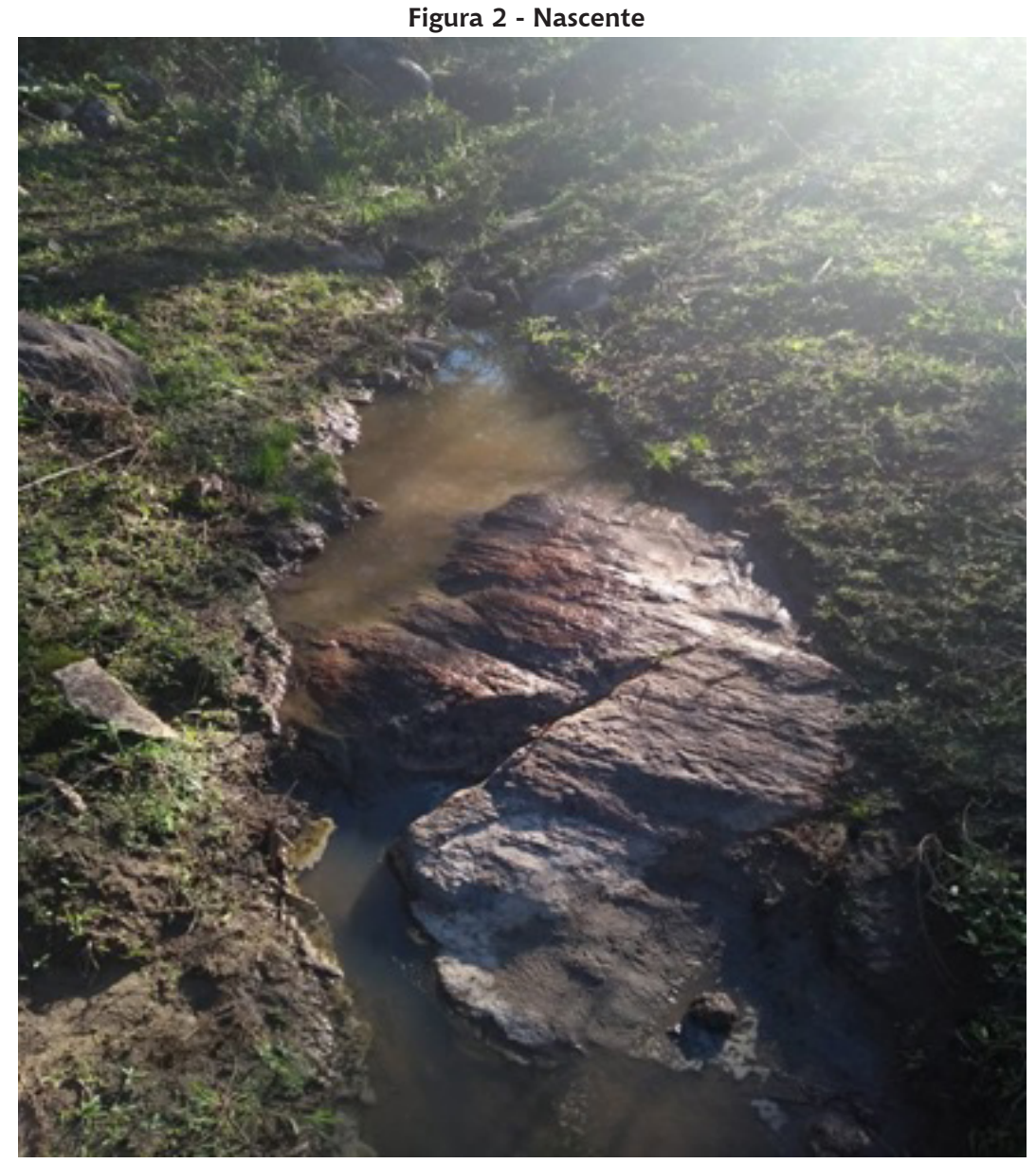

Fonte: arquivo pessoal das pesquisadoras.

Essa persistência nos conduz ao movimento, persistir exige movimento, seja como nascente ou como professora. Essas são as principais pistas com as quais nos deparo na narrativa da minha parceira e na conversa com Priscila Fernandes, Gabriel Viana e Giovana Scareli (2016).

Partindo de um pressuposto de que o mundo se nos apresenta mutável, podemos desvelar a afirmação de que o movimento é parte essencial do tornar-se professora. Tornar-se professora é um processo curvilíneo, e diariamente reinventado, ele não diz respeito a técnicas de abordagem de conteúdo, nem é garantido por títulos acadêmicos, segundo Fernandes, Viana e Scareli (2016, p. 228) "[...] é um movimento inacabado, um caminho do meio". Assim compreendemos que o constante movimento traduz o que 
já vimos anunciando no decorrer desse plantio, sujeitos dispostos e desejosos por reinventar-se, produzindo diferenças em si e no outro, sujeitos do devir.

Dialogar essa imagem com a fala da nossa parceira de cartografia tem também o sentido de pensar sobre os sentidos dos nossos movimentos docentes: que não caiamos na armadilha da rigidez e do enquadramento, o que poderia tornar o professor em um "[...] dador de aulas". (PEREIRA, 2016, p. 205)

\section{Colhendo professoralidades de experiências docentes no campo}

O exercício de escrever sobre movimentos professorais nos permitiu, entre outros atravessamentos, pensar no caráter político de cada uma de nossas trajetórias professorais, além de refletir sobre como as diferentes maneiras de viver a experiência pode reverberar em outras possibilidades de ação e (trans)formação, sobretudo no que concerne a estratégias de resistência às atuais e perversas propostas educacionais e seu caráter neoliberal.

Compreender a diferença como base do nosso processo de (trans)formação professoral, nos permitiu refletir sobre o fato de que ela é responsável pelos acordos e tensionamentos estabelecidos nos docentes por meio da experiência, que é o mote deste plantio cartográfico. Através da partilha de experiências, pudemos perceber que há muito de coletivo em nossos atravessamentos pessoais, afetando nossas professoralidades, ainda que de maneiras distintas.

Entendemos que precisávamos nos deslocar, que havia mudanças em curso na comunidade rural... As famílias já não têm mais a lida na roça como principal meio de sustento, a proximidade com o centro do município e a possibilidade de um transporte coletivo com regularidade dava uma outra roupagem às relações escolares. Então, encontrávamos aí diferenças que fazem diferença...

As diferenças às quais me refiro não tem um sentido identitário, estabelecido a partir da perspectiva da representação- as supostas características específicas de cada indivíduo ou grupo que os distinguiriam de todos os outros. Ao contrário, refiro-me às diferenças no sentido daquilo que justamente vem abalar as identidades, estas calcificações de figuras, opondo-se à eternidade. O inatual, o intempestivo. Diferenças que fazem diferença. (ROLNIK, 1995, p. 1) 
Por outro lado, a partir da narrativa de nossa parceira de cartografia e da imagem eleita para expressar o atravessamento que a sua fala produziu em nós, entendemos que somos desafiadas constantemente a encontrar nascentes para irrigar nosso movimento de estar-sendo professoras. Assim como quando precisamos das nascentes que garantem o abastecimento de água para a comunidade, ou quando pedimos que o clima seja bom para que a colheita seja farta. Ao percorrer esses caminhos da roça, nos deparamos com diversos desafios, os quais nos permitiram a ressignificação de diversos sentidos de estar-sendo professora, o que tem sido determinante para (trans)formar e retomar experiências.

\title{
When bean planting moves us: experiences and experimentations in natural sciences in country education
}

\begin{abstract}
This paper presents an excerpt from a cartographic research inspired by a school memory experienced in elementary school. In this memory, the experiment had the propose to observe the germination process of beans in a container with moistened cotton. This memory moves me to research and think about this experiment, not only because of the discomfort that it made, but also because of the experience that crossed me that time. Inspired by the crossings that this memory has been producing and the notion of experience proposed by Jorge Larrosa, this research aims to accompany the production of memories of teachers involved with country education. Therefore, narrative interviews and visual images are considered important devices of this cartography. A teacher from a country school was invite to talk about her teaching career, in order to understand the production of differences that permeate the construction of professoralities, considering the memories and events that has been moving her teaching trajectory. Understanding the difference as the basis of our teacher (trans)formation process allowed us to think about how the experience is important for this cartographic planting. Through the sharing of experiences, we could understand that there is a lot of collective in our personal crossings, affecting our professoralities in different ways.
\end{abstract}

Key-words: cartography; (auto)biography; imagetic experience.

\section{Cuando la siembra de frijoles nos cruza: experiencias y experimentos en ciencias naturales en el campo}

Resumen: Este artículo trata de un extracto de nuestra investigación cartográfica, que surge de una memoria escolar experimentada en la escuela primaria: el experimento que estaba destinado a seguir el proceso de germinación de frijoles en un recipiente con algodón humedecido. La realización de este experimento provocó cruzamentos que nos afectaron y nos movilizaron para construir nuestra escritura, tomando esta memoria como potencia a partir del cual comienzan las reflexiones en torno a la noción de experiencia (a partir de los escritos de Jorge Larrosa). Pensando en los cruzamientos que 
este recuerdo ha estado produciendo en nuestros ser maestras, proponemos como objetivo de este estudio acompañar los procesos de producción de recuerdos docentes, que visem expresar profesoralidades en el campo, considerando entrevistas narrativas, vinculadas a imágenes visuales, como dispositivos para "hacer ver y hacer hablar", tomando a Gilles Deleuze como inspiración. En este artículo, 1lamamos a una maestra de una escuela en el campo, para acompañar la producción de diferencias que impregnan nuestras profesoralidades, a través de nuestros recuerdos y los eventos que pasan por nosotros. Comprender la diferencia como la base de nuestro proceso de (trans)formación docente, nos permitió reflexionar sobre el hecho de que ella es responsable de los acuerdos y la tensión establecidos en los maestros a través de la experiencia, cual es el lema de esta plantación cartográfica. Al compartir experiencias, pudimos darnos cuenta de que hay mucho de colectivo en nuestros cruzamientos personales, lo que afecta a nuestras profesoralidades, aunque de diferentes maneras.

Palabras clave: cartografía; (auto)biografía; experiencia imagética.

\section{Referências}

CAMARGO, N. S. J. de; BLASZKO, C. E.; UJIIE, N. T. O ensino de ciências e o papel do professor: concepções de professores dos anos iniciais do ensino fundamental. In: EDUCERE. CONGRESSO NACIONAL DE EDUCAÇÃO, 12., 2015, Curitiba. Anais [...]. Curitiba, 2015, p. 1-16. Disponível em: https://educere.bruc.com.br/arquivo/ pdf2015/19629_9505.pdfhttps://educere.bruc.com.br/arquivo/ pdf2015/19629_9505.pdf. Acesso em: 23 dez. 2019.

CINTRA, A. M. S. et al. Cartografia nas pesquisas científicas: uma revisão integrativa. Fractal: Revista de Psicologia, [Niterói], v. 29, n. 1, p. 45-53, 2017. Disponível em: http://www.scielo.br/pdf/fractal/ v29n1/1984-0292-fractal-29-01-00045.pdf. Acesso em: 23 dez. 2019.

COSTA, L. B. da. Cartografia: uma outra forma de pesquisar. Revista digital do LAV, [Santa Maria], v. 7, n. 2, p. 66-77, 2014. Disponível em : https://periodicos.ufsm.br/revislav/article/view/15111/pdf_1. Acesso em: 23 dez. 2019.

COSTA, S. S. O. Caminhos para o conhecimento de si: narrativas auto(biográficas) na formação inicial/continuada de professores. In: COLÓQUIO INTERNACIONAL EDUCAÇÃO E CONTEMPORANEIDADE, 6. 2012, São Cristóvão. Anais [...]. São Cristóvão, 2012, p. 1-10. Disponível em: http://educonse.com.br/2012/ eixo_04/PDF/51.pdf. Acesso em: 23 dez. 2019.

DELEUZE, G. O que é um dispositivo. Lisboa: Ed. Veg, 1996. Disponível em: http://www.uc.pt/iii/ceis20/conceitos_dispositivos/programa/ deleuze_dispositivo. Acesso em: 23 dez. 2019.

DELEUZE, G.; GUATTARI, F. Mil Platôs: capitalismo e esquizofrenia. 2. ed. São Paulo: Editora 34, 2011. v. 1. 
FERNANDES, P.; VIANA, G.; SCARELI. O espaço sempre inacabado do tornar-se professor: a construção do meio. Educação em Foco, Juiz de Fora, v. 21, n. 1, p. 215-236, 2016. Disponível em: https://periodicos.ufjf. br/index.php/edufoco/article/view/19664. Acesso em: 23 dez. 2019.

FERREIRA, T. R. Experiências (auto) formativas na narração da história de vida de duas professoras: caminhos do ser-fazer docente. 2016. Dissertação (Mestrado em Educação) - Universidade Federal de São João Del-Rei, São João Del Rei, 2016. Disponível em: https://ufsj. edu.br/portal-repositorio/File/mestradoeducacao/Dissertacao\%20 Thalita\%20Rodrigues\%20Ferreira.pdf. Acesso em: 23 dez. 2019.

GALLO, S. D. de O. Algumas notas em torno da pergunta: 'o que pode a imagem?'. Revista Digital do LAV, [Santa Maria], v. 9, n. 1, p. 16-25, 2016. Disponível em: https://periodicos.ufsm.br/revislav/article/ view/21766/pdf_1. Acesso em: 23 dez. 2019.

GIORDAN, M. O papel da experimentação no ensino de Ciências. Revista Química Nova na Escola, [São Paulo], n.10, p. 43-49, 1999. Disponível em: http://qnesc.sbq.org.br/online/qnesc10/pesquisa.pdf. Acesso em: 23 dez. 2019.

LARROSA, J. Tremores: escritos sobre experiência. Belo Horizonte: Autêntica Editora, 2018.

LARROSA, J. Experiência e Alteridade em Educação. Revista Reflexão e Ação, Santa Cruz do Sul, v. 19, n. 2, p. 4-27, 2011. Disponível em: https://online.unisc.br/seer/index.php/reflex/article/view/2444/1898. Acesso em: 23 dez. 2019.

LARROSA, J. Notas sobre a experiência e o saber da experiência. Revista Brasileira de Educação, [Rio de Janeiro], n. 19, p. 20-28, 2002. Disponível em: http://www.scielo.br/pdf/rbedu/n19/n19a02.pdf. Acesso em: 23 dez. 2019.

LARROSA, J. Tecnologias do eu e educação. In: SILVA, T. T. (org.). O Sujeito da educação. Petrópolis: Vozes, 1994.

NORA, P. Entre memória e história: a problemática dos lugares. Projeto História, São Paulo, v. 10, p. 7-28, 1993. Disponível em: https://revistas. pucsp.br/revph/article/view/12101/8763. Acesso em: 23 dez. 2019.

PALANDI, V. Por que o feijão nasce no algodão? ColegioWeb, 2016. Disponivel em: https://www.colegioweb.com.br/educador/por-que-ofeijao-nasce-no-algodao.html. Acesso em: 1 jul. 2019

PASSOS, E.; BARROS, R. B. A cartografia como método de pesquisaintervenção. In: PASSOS, E.; KASTRUP, V.; ESCÓSSIA, L. da (org.). Pistas do método da cartografia: pesquisa intervenção e produção de subjetividade. Porto Alegre: Sulina, 2015.

PEREIRA, M. V. Estética da professoralidade: um estudo crítico sobre a formação do professor. Santa Maria: Ed. da UFSM, 2016. 
ROLNIK, S. Cartografia sentimental: transformações contemporâneas do desejo. Porto Alegre: Editora UFRGS, 2006.

ROLNIK, S. O mal-estar na diferença. São Paulo: PUC-SP, 1995.

Disponível em: https://www.pucsp.br/nucleodesubjetividade/Textos/ SUELY/Malestardiferenca.pdf. Acesso em: 23 dez. 2019.

SOUZA, E. C. O conhecimento de si: narrativas do itinerário escolar e formação de professores. 2004. Tese (Doutorado em Educação) Faculdade de Educação, Universidade Federal da Bahia, Salvador, 2004. Disponível em: https://repositorio.ufba.br/ri/bitstream/ri/10267/1/ Tese_Elizeu\%20Souza.pdf. Acesso em: 23 dez. 2019.

SOUZA, E. C. A arte de contar e trocar experiências: reflexões teóricometodológicas sobre história de vida em formação. Revista Educação em Questão, Natal, v. 25, n. 11, p. 22-39, 2006. Disponível em: https:// periodicos.ufrn.br/educacaoemquestao/article/view/8285/5958.

Acesso em: 23 dez. 2019.

VAZ, T. Docência em deriva: atravessamentos de um 'devir professor'. In: SEMINÁRIO DE PESQUISA EM EDUCAÇÃO DA REGIÃO SUL, 9., 2012, Caxias do Sul. Anais [...]. Caxias do Sul, 2012. p. 1-15. Disponível em: http://www.ucs.br/etc/conferencias/index.php/anpedsul/9anpedsul/ paper/viewFile/1243/790. Acesso em: 23 dez. 2019.

WUNDER, A. Uma educação visual por entre Literatura, Fotografia e Filosofia. Políticas Educativas, Porto Alegre, v. 3, n. 1, p. 65-78, 2009. Disponível em: https://seer.ufrgs.br/Poled/article/view/22532/13065. Acesso em: 23 dez. 2019. 